Int. J. Electrochem. Sci., 15(2020) $4379-4387$

International Journal of

ELECTROCHEMICAL

SCIENCE

WWW.electrochemsci.org

\title{
Preparation of Chemically Modified Porous Carbon Networks Derived from Citrus Sinensis Flavedos as Electrode Material for Supercapacitor
}

\author{
Malathi Devendran ${ }^{1}$, Senthil Kumar Kandasamy ${ }^{1,}$, Shanmugam Palanisamy ${ }^{2}$, Sangavi Selvaraj ${ }^{1}$, \\ Ragavi Vetrivel ${ }^{l}$, Roobak Selvarajan ${ }^{l}$, Murugesan Govindasamy ${ }^{l}$, \\ Kannan Kandasamy ${ }^{2}$ \\ ${ }^{1}$ Department of Electronics and Communication Engineering, Kongu Engineering College, Erode- \\ 638060, India \\ ${ }^{2}$ Department of Chemical Engineering, Kongu Engineering College, Erode-638060, India \\ *E-mail: senthilkumar6k@gmail.com
}

doi: $10.20964 / 2020.05 .08$

Received: 22 November 2019/ Accepted: 13 February 2020 / Published: 10 April 2020

This work has mainly focused on the development of a type of porous nitrogen doped carbon networks derived from green biomass waste (citrus sinensis flavedos) by carbonization and activation. Different chemical activations using sulphuric acid, hydrochloric acid and phosphoric acid are employed to obtain improved specific capacitance. From the XRD results, broad peak was observed at $24^{\circ}$. The performance of citrus sinensis flavedos derived carbon materials for supercapacitor applications is evaluated using aqueous electrolyte $\left(0.5 \mathrm{M} \mathrm{H}_{2} \mathrm{SO}_{4}\right)$ at various current densities and scan rate of 30 $\mathrm{mV} \cdot \mathrm{s}^{-1}$. The superior performance of the derived nanoporous carbon is attributed to high surface area with fast ionic and electronic diffusion of the electrolyte in and out of the pores. From CV analysis, the electrodes OPC, OPCH, OPCP and OPCS in $0.5 \mathrm{M} \mathrm{H}_{2} \mathrm{SO}_{4}$ aqueous electrolyte exhibit the specific capacitance of 39, 28, 92 and $88 \mathrm{~F}^{-\mathrm{g}^{-1}}$ respectively, with improved capacity retention ratio. From GCD measurement, the specific capacitances are calculated as 52, 19, 169 and $35 \mathrm{~F}^{-1}{ }^{-1}$ for OPC, OPCH, OPCP and OPCS respectively at $0.25 \mathrm{~mA} \cdot \mathrm{g}^{-1}$. When compared to chemically activated samples, pure citrus sinensis flavedos exhibited small equivalent series resistance.

Keywords: Citrus Sinensis Flavedo, Chemical Activation, Supercapacitor, Specific Capacitance

\section{$\underline{\text { FULL TEXT }}$}

(C) 2020 The Authors. Published by ESG (www.electrochemsci.org). This article is an open access article distributed under the terms and conditions of the Creative Commons Attribution license (http://creativecommons.org/licenses/by/4.0/). 
